\title{
Childhood obesity prevention studies: lessons learned and to be learned
}

\author{
MBE Livingstone*, TA McCaffrey and KL Rennie
}

School of Biomedical Sciences, Northern Ireland Centre for Food and health, University of Ulster, Coleraine, Northern Ireland BT52 1SA, UK

Submitted 18 April 2006: Accepted 16 November 2006

\begin{abstract}
Objective: To provide an overview of methodological issues in the design, delivery and evaluation of childhood obesity prevention programmes.

Design: Review of existing literature.

Setting: International.

Results: Interventions have varied considerably with regard to their design, subject selection criteria, sample size, attrition rates, intervention components and duration of both the intervention and the follow-up phases. However, overall, there is only a limited body of consistent, high-quality evidence on which valid and generalisable conclusions can be drawn about best practices for the prevention of childhood obesity. Conclusions: Although the rationale for targeting children and adolescents through primary prevention is now compelling, effective obesity prevention remains elusive. There is increasing consensus that prevention of childhood obesity necessitates multifaceted health promotion interventions based on population health principles. By definition, such interventions should have a range of outcome indicators of effectiveness, generalisability and sustainability, not just the traditional ones focused on individual lifestyle behaviour change. Given the complexity and intricacy of population-based intervention programmes, multiple methods of data collection which combine both qualitative and quantitative approaches will need to be fully exploited in order to move towards evidence-based practice in the future.
\end{abstract}

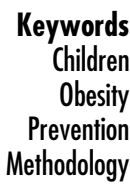

\section{Introduction}

The prevention of childhood obesity is now a global priority. This reflects the fact that during the past two decades rates of obesity have escalated sharply in both developed and developing countries ${ }^{1,2}$, but to date no country has been able to arrest, let alone reverse these trends. The physical and psychological consequences of childhood obesity are serious and far reaching. First, obese children tend to become obese adults ${ }^{3-5}$ with approximately one in five obese 4-year-olds becoming obese adults rising to approximately four in five by adolescence. Secondly, obesity in childhood has a significant immediate impact on physical health as well as predicting adult morbidity and mortality ${ }^{6-8}$. The antecedents of adult disease (hypertension, dyslipidaemia, hypercholesterolaemia, hyperinsulinaemia, impaired glucose tolerance and type 2 diabetes mellitus) are now occurring with increasing frequency in obese children as young as 5 years $^{9,10}$. Irrespective of their adult weight, adults who were obese as children also have an increased risk of morbidity and mortality ${ }^{6,11}$. Overweight and obesity in childhood/adolescence are also known to have a significant adverse impact on psychological well-being, causing many children to be negatively stereotyped ${ }^{12}$ and to experience low self-esteem and negative self-image ${ }^{13-15}$. Thirdly, many of the adverse eating and activity behaviours that are known to promote obesity and which are learned early in life within the family context may track into adulthood ${ }^{16-18}$.

Once established, obesity is a protracted and difficult to treat condition. Although treatment approaches to paediatric obesity may be effective in the short-term, long-term studies indicate high rates of relapse after treatment ${ }^{19}$. Moreover, as more and more children become obese, treatment needs are already outstripping treatment resources. Notwithstanding the compassionate need to treat established obesity in children and adolescents, few would argue that the only feasible, and ultimately costeffective approach for dealing with the problem is to prevent it happening in the first place. Since most children at risk of future obesity cannot be identified easily in childhood, a population-based preventive approach aimed at lowering the overall prevalence of risk factors 
for obesity and subsequent disease has been advocated ${ }^{7}$. In this way, all children regardless of their obesity risk status would be targeted based on the reasonable assumption that every child would be expected to benefit from interventions which promote a healthy diet and active living.

Although the rationale for targeting children and adolescents through primary prevention is now compelling, effective obesity prevention remains elusive and there is no consensus about the optimal age to intervene at a population level and what preventive measures need to be enacted. This is probably due to the extremely complex set of factors determining excess weight gain and the multiple social, cultural and economic factors associated with food intake and physical activity behaviours. Although many of the risk factors are related and appear obvious, it is far from clear how they may cluster, cumulate or confound each other in determining the causal pathway to the development of obesity ${ }^{20}$. Although not an exhaustive list, the most consistently observed risk factors for childhood obesity include a family history of obesity, low socio-economic status, early rapid weight gain, early timing or rate of maturation, low physical activity or high inactivity, dietary intake and composition (including early infant feeding practices) and psychological factors ${ }^{4}$. Although parental overweight is a strong risk factor for childhood obesity, it is highly unlikely that the burgeoning rates of childhood obesity over the past two decades in genetically stable populations have a biological basis. It is now widely acknowledged that the causes of childhood overweight can be largely attributed to an increasingly obesogenic environment which is exerting increasing pressure on children to overeat and at the same time is conspiring to make them more and more inactive. In turn, this implies that prevention of childhood obesity cannot be left to individuals, or indeed families, but necessitates a multi-strategic approach involving all levels of society to counter adverse environmental influences on dietary and physical activity behaviours.

Perhaps, not surprisingly, concern about the dramatic increase in childhood obesity worldwide has resulted in a rush to develop and disseminate prevention programmes. These programmes have varied considerably with regard to study design, subject selection criteria, sample size, attrition rates, intervention components and duration of both the intervention and the follow-up phases but overall, there have been relatively few primary prevention studies which have been rooted in population health principles. Although there have been numerous systematic reviews of these studies, variations in outcome measures, intervention components and length of follow-up periods between studies precludes formal meta-analyses of results. Moreover, the systematic reviews, many of which have been published in the past 6 years, have varied in both scope and focus and depending on the exclusion/inclusion criteria adopted, the number of interventions deemed suitable for inclusion have varied considerably.

The earlier reviews tended to adopt a more specific and narrow appraisal focus, usually based on the methodological rigour of the intervention programmes. For example, some have restricted their inclusion criteria to interventions with a randomised control design while others, because of the lack of evidence from such trials, have included controlled trials without randomisation, but with parallel control groups. In some reviews, the focus has been on interventions targeting obese children only ${ }^{21}$, others have embraced both treatment and prevention ${ }^{22,23}$, while some have concentrated solely on the prevention of obesity $^{24}$ or weight gain ${ }^{25}$. Some reviews specifically focussed on physical activity interventions to treat and/or prevent childhood obesity ${ }^{26,27}$. Since many obesity prevention programmes have been school based, these have been the exclusive focus in reviews by Story ${ }^{28}$, Resnicow $^{29}$ and Doak et al. ${ }^{30}$. Finally, given the paucity of studies where the intervention and/or follow-up phases lasted for a minimum of 1 year, shorter term studies have also been included in many reviews, e.g. Summerbell et $a l .{ }^{24}$ and Doak et al. ${ }^{30}$

In contrast to the earlier reviews in which methodological rigour was the main yardstick by which intervention studies were appraised, more recent reviews have intentionally been more inclusive and diverse in their appraisal process in order to identify elements of best practice for the prevention of obesity at the population level ${ }^{24,30,31}$. Without doubt, the most comprehensive and inclusive synthesis of the literature to date has been the one carried out by Flynn et $a l^{31}$ in which 500 reports were evaluated not only for their methodological rigour, but also for programme development/evaluation and the degree to which they encompassed the principles of population health and immigrant health.

Overall, based on the evidence to date, there is only a limited body of consistent, high-quality evidence on which valid and generalisable conclusions can be drawn about best practices for the prevention of childhood obesity. As highlighted by recent systematic reviews, including a number of policy-driven evidence reviews, there are relatively few proven effective obesity prevention approaches for children at the present time. Thus, while many primary prevention programmes have demonstrated (to varying degrees) improved knowledge, health-related attitudes and even self-reported physical activity and dietary behaviours, they have achieved limited success in modifying weight status, at least in the longer term.

What lessons can be learned from both the successes and the shortcomings of past interventions, which will help guide research and optimise the development, delivery and effectiveness of prevention programmes in the future? 


\section{Design of prevention studies}

Until recently, randomised controlled trials (RCT) have been considered the gold standard methodology for building a robust evidence base for the prevention of childhood obesity. Indeed, most of the systematic reviews in the area have overwhelmingly focussed on those studies which have adopted this study design, albeit that many of them have been methodologically flawed. Of late, there has been increasing concern that while such studies offer, in theory at least, the best potential to be free from bias, they may not be best suited for conducting and evaluating complex and multifaceted health promotion interventions based on population health principles ${ }^{2,32}$. By their nature, multifaceted interventions are likely to have a range of outcome indicators of effectiveness, generalisability and sustainability, not just the traditional ones focused on individual lifestyle behaviour change. Given the complexity and intricacy of population-based intervention programmes, multiple methods of data collection which combine both qualitative and quantitative approaches will need to be fully exploited in order to move towards evidence-based practice in the future.

\section{Lack of focus of interventions}

Although there is consensus that a multifaceted approach involving all levels of society is needed for effective obesity prevention, population health approaches to the problem have traditionally focussed on the individual through such strategies as education and behaviour change programmes. However, naïve enthusiasm and simple messages with regard to obesity-promoting lifestyle behaviours will not solve the problem because while this may be sufficient motivation for some individuals to change their behaviours, it is clearly not a sufficient motivation for the majority. In fact, the health benefits of dietary and physical activity change are likely to be some of the weakest motivators of change in nonclinical populations and it could be argued that they might even undermine efforts to increase the perceived value of healthy behaviours. Probably the factor which has received least, but arguably needs the most attention in the design and delivery of many obesity preventing programmes is motivation or incentives to adopt the new (desirable) behaviour. In children and adolescents, the immediate impact and consequences (often unrelated to health) of performing a health-related behaviour is likely to be critical for its adoption and maintenance. For example, dance (perceived to be a highly motivating and enjoyable activity for many girls) in place of more traditional physical education classes (often much less attractive) may get girls to engage in regular and sustained bouts of low to high-intensity physical activity without them ever having to be bothered about the associated health benefits.

If health professionals are to intervene more effectively in preventing childhood obesity, they need to have a complete appreciation and understanding of how the lifestyle behaviours that promote obesity are adopted and sustained and of the factors that both motivate and constrain change. In effect, obesity prevention needs to be viewed as more of a behavioural challenge than purely a nutrition/lifestyle problem. Regrettably, when documenting intervention outcomes, very few studies to date have reported the mechanisms of, and barriers to, changing these lifestyle behaviours, presumably because they were never assessed in the first place. It is perhaps not surprising that the more successful interventions have been conceptually grounded in behaviour change theory, although it is difficult to establish, based on the published information on these studies, if the theoretical underpinning to programme development and delivery was a critical driver of the success of the programme.

In particular, social ecological models, in which behaviour is hypothesised to be a function of the reciprocal interaction between personal, behavioural and environmental factors, provide some of the best suited frameworks on which to base population level health promotion interventions ${ }^{33-35}$. These models recognise that children's obesity-promoting behaviours cannot be understood, or interventions to change them succeed, without taking into consideration the complex and multidimensional micro- and macro-level contexts in which their physical activity and dietary behaviours are shaped, mediated, moderated and maintained ${ }^{36}$.

Although these models emphasise multi-component interventions which target different spheres of influence simultaneously, admittedly, it would be extremely challenging, if not impossible, to fully implement changes at all levels in a single intervention. To date, most programmes have either focussed on a single level, for example, individual education in school-based interventions or at two levels (individual education plus local environmental changes such as the school food environment). Typically, a number of strategies within each level are implemented, for example, changes in the nutritional composition of school meals, healthy snack foods available from vending machines and operating a food pricing structure in favour of healthy snacks. Based on the evidence to date, it is clear that multi-component interventions result in more positive outcomes on individual food choices and $\operatorname{diet}^{37-39}$. Inevitably, however, if a paradigm shift that emphasises the importance of understanding individual behaviour within the larger environmental context in which people live is to materialise, it will require new collaborations and partnerships between experts who, traditionally, have had little influence on obesity research, for example, between urban planners, architects, transportation agencies, physical activity researchers, behavioural scientists and public health researchers in order to positively impact on physical activity levels. 


\section{Issues of bias}

One of the most striking observations by Flynn et al. ${ }^{31}$ is that $85 \%$ of the 147 studies which were included in their final synthesis were, to a greater or lesser extent, methodologically flawed by selection bias, information bias and/or confounding. The potential for selection bias was identified in many studies. Examples include: the recruitment of unrepresentative and inadequately powered samples, unacceptably high attrition rates and loss to follow-up, particularly without reporting the characteristics of 'completers' and 'non-completers' with which to allow an informed assessment of the potential for bias. Some studies have not included a control or comparison group or have adopted a cross-over study design making it almost impossible to assess the effectiveness of the interventions and almost certainly enhancing the likelihood of drawing false causal inferences about the outcomes. Other sources of bias include inadequate randomisation into test and control groups, inadequate allocation concealment and failure to control all variables other than the intervening ones. In practice, of course, control conditions are extremely difficult to implement in the context of health promotion interventions. Contamination of the control group remains a constant threat and as a result, this may lead to an underestimation of any effect observed in the intervention group. Finally, unit of analysis errors are not uncommon in intervention studies since most school-based studies tend to randomise by school or class but perform the analysis on the basis of individual children. Unless these are statistically accounted for through cluster analysis, the outcomes are likely to be misleadingly optimistic. Finally, the potential for confounding is a major problem in health interventions and although it is well nigh impossible to control for them all, some studies are at fault for not giving due consideration to such factors as parental adiposity and socio-economic factors in the design, delivery and analysis of their interventions.

\section{Measuring bebavioural outcomes}

In order to monitor the impact of intervention strategies on childhood adiposity, as well as for comparative purposes, the ability to measure key outcomes and determinants of interest, particularly body composition, eating and physical activity behaviours and attitudes and psychosocial variables, is crucial. Unfortunately, obtaining valid and precise measures of exposure and outcome variables, particularly dietary and physical activity variables, is fraught with difficulty and this has been a major problem for most studies. In the absence of objective measures, studies have had to rely on participant self-reports of their obesity-related lifestyle behaviours. However, in the context of nutritional and/or physical activity interventions where subjects are receiving constant advice about the desirability of behaviour change, self-reports of these behaviours are particularly vulnerable to bias through socially desirable responding and/or the need to achieve a self-presentation goal. In effect, it is highly probable that food (energy) intake will be under-reported while physical activity patterns will be over-estimated, making it impossible to distinguish between true effects of the intervention and biased reporting ${ }^{40}$. Biased self-reports are likely to at least partially account for the apparent paradox where there appears to have been beneficial lifestyle changes but where there has been no corresponding impact on body weight or composition. In the case of physical activity, objective and cost-effective methods of assessing this behaviour, such as accelerometers, are now available and their use is strongly advocated in future studies. Unfortunately, no such objective measure of dietary intake exposures and outcomes are currently available, and while this should not negate attempts to measure dietary intake, researchers should always scrutinise dietary data for reporting bias using established techniques ${ }^{41}$.

In order to monitor prevalence trends and assess the impact of prevention programmes on adiposity status, suitable physiological outcome measure (s) are required. Body mass index (BMI) remains one of the most feasible surrogate markers of fatness in epidemiological studies in children, but with certain caveats. Given the short time frame of many interventions, unless the intervention is designed to bring about rapid change in body weight, BMI is unlikely to capture any change in adiposity. Consideration also needs to be given to the inclusion of both waist circumference measurement as an indirect indicator of intra-abdominal adiposity and more direct measures of adiposity status such as skin-fold thicknesses, albeit that the latter are particularly prone to measurement error. In total, these assessments would contribute to a clearer understanding of intervention effects on body composition and fat distribution. This is especially important in interventions with a focus on increasing physical activity where there may be no change, or even an increase, in outcome BMI but where there are simultaneous reductions in skin-fold measures, indicating an increase in lean body mass with corresponding reductions in adiposity $^{42}$. Finally, from the point of view of being able to quantitatively assess and compare effect outcomes from different studies, it makes sense that researchers should reach consensus about reporting their outcomes in standardised ways. In particular, as advocated by Doak et $a l .{ }^{30}$, the frequency distribution for the outcome variables should be presented in order to evaluate the impact of the chosen intervention on the whole target population.

\section{Duration of subject follow-up}

A common concern raised by virtually all reviews is the paucity of interventions which have followed up study participants over the longer term. At present, while there is no consensus about the optimal duration of follow-up, it is 
often tacitly assumed that long-term follow-up should be for a period of at least 1 year. Even then, this is a relatively short period for evaluating the health effects of obesity interventions in children. Thus, while many short-term studies have shown beneficial changes in dietary and/or physical activity habits it has been impossible to ascertain whether these lifestyle changes have been maintained over time. However, it is well documented that short-term improvements in dietary and physical activity habits are extremely difficult to sustain in the longer term and this may partially explain why studies of longer duration generally show less positive outcomes. Given the possibility of biased conclusions based on the outcomes of 'successful' short-term interventions, considerable caution needs to be exercised in drawing any conclusions about the generalisability of the results of such studies for the longer term. Nevertheless, the merit of short-term studies for piloting the feasibility and acceptability of a potential intervention should be acknowledged.

\section{Do no barm!}

One of the guiding principles of any obesity prevention programme is that it should do no harm ${ }^{43}$. In relation to childhood obesity, the potential for stigmatising obese children, and for promoting a negative self-image and eating disorders in normal weight children, although unintentional, has not been assessed in the majority of interventions. However, two recent reports ${ }^{44,45}$ have assessed these issues in their interventions and have reported no adverse outcomes. While this is encouraging, as efforts to stem the childhood obesity epidemic are likely to intensify, future programmes should give much more emphasis than hitherto, to improving and maintaining children's emotional well-being and be alert to the potential for promoting negative attitudes and behaviours.

\section{Its never too early to intervene ... and otber neglected areas}

Ultimately, the most desirable goal in childhood obesity is to prevent children from becoming at risk of obesity in the first place, a goal which is more likely to be achieved if prevention strategies and interventions are initiated in the first few years of life and sustained during childhood and adolescence. However, a scrutiny of the literature shows an almost total absence of such interventions, despite the accumulating evidence that early life events related to intrauterine and post-natal growth may represent 'critical' time windows which have consequences for long-term growth and development. Several cohort studies have identified that rapid growth-especially weight gainduring infancy, be it at 4, 6, 12 or 24 months of age, predicts future obesity in children and adults ${ }^{46-48}$. Rapid early weight gain, particularly in children who are born small for gestational age, may also favour central fat deposition $^{49-51}$. To what extent early infant feeding practices, particularly whether exclusive breast or formula feeding can reduce or promote the risk of later obesity, is a much debated and controversial issue $e^{52-55}$. Some studies have suggested that at least part of this controversy may have been due to the use of surrogate (BMI) rather than direct (DXA) measures of adiposity which may have artificially inflated the protective effect of breastfeeding on later obesity $^{56-58}$. In practice, of course, decisions about duration of breastfeeding or introduction of formula feeding are not independent at all, and it is their association which probably explains the variability in obesity risk status. Moreover, this association is probably driven by multiple and complex parental and infant factors which currently are poorly understood, but whose clarification is required to inform safe and effective dietary and behavioural interventions in early infancy. Clearly, the ante-post-natal period is a critical window of opportunity to intervene effectively in obesity prevention which justifies not only more research but also a broader methodological approach to assembling evidence of effectiveness.

Given the 'captive' nature of the audience, the majority of obesity prevention programmes for children and adolescents have been conducted in schools. In contrast, there has been a dearth of programmes which have specifically targeted parents or the home environment, probably due in part to the logistical difficulties associated with implementing interventions in such settings. Although $52 \%$ of the programmes reviewed by Flynn et $a l .{ }^{31}$ did involve families directly or indirectly, their levels of engagement and respective contribution to programme effectiveness are difficult to evaluate. Families typically share dietary, activity and sedentary habits and traits and the family environment is pivotal in both the evolution of a child's overweight condition and its resolution ${ }^{36}$. However, getting parents to actively participate in prevention programmes may be difficult, and even when they do so, family-focussed interventions have resulted only in modest, short-term outcomes on dietary behaviours, but not on longer term positive changes on adiposity measures ${ }^{59}$.

Most family-based interventions have been concerned with addressing treatment rather than prevention of obesity. It is clear from these treatment studies that family-orientated therapy produce better outcomes than a child-only approach ${ }^{19}$. In particular, interventions that have focussed on parents as the 'agents of change' have proven to be effective in helping to reduce children's weight, both in the short and in the long term ${ }^{60,61}$, and it is reasonable to assume that such strategies could prove effective when applied to the prevention model. Just as an obese child cannot be effectively treated in isolation of the family, it is also inconceivable that prevention of obesity can be achieved in isolation of, or indeed solely by, the family. Although parents have a unique and pivotal role in determining a child's risk of future obesity, a detailed evidence base on the context of parenting and the 
constraints, and opportunities under which parents operate, is virtually non-existent. This research gap will need to be addressed as an essential prerequisite for informing the design and implementation of successful family-based obesity prevention strategies for children.

Another neglected area in childhood obesity prevention research has been the failure to take account of specific gender and ethnicity needs and issues. Out of five interventions which showed gender differences in outcomes, two with a physical activity focus were found to be effective only for boys ${ }^{62,63}$, while three other interventions demonstrated positive outcomes only in girls ${ }^{64-67}$. This suggests that potential gender differences in prevention efforts merit further investigation in order that future programmes are better tailored to meet gender needs. However, very few of the programmes reviewed by Flynn et $a l .{ }^{31}$ had a gender-specific focus and these were mainly in favour of girls, while boys were particularly underserved. The bias towards targeting girls has been justified on the grounds of their decreased participation in physical activity, particularly during adolescence, their heightened preoccupation with body image and increased vulnerability to eating disorders. On the other hand, the specific health risks posed by obesity in boys have rarely been catered for in prevention programming. Similarly, the paucity of programmes addressing the unique needs of minority ethnic groups and the vulnerability of immigrants to the obesogenic environments of host industrialised countries have also been highlighted ${ }^{31,68}$.

\section{Evaluation of intervention programmes}

Despite the large number of potentially useful interventions which have taken, or are currently taking place, it is still not possible to draw definitive conclusions and make specific recommendations about which components of these interventions have the potential to be rolled out on a larger scale, be sustainable in the medium to longer term and have a high likelihood of making a substantive impact on the prevalence of childhood obesity. Unfortunately, the bias towards publishing studies with positive outcomes has not been helpful in this respect. As pointed out by Doak et $a l .{ }^{30}$, the outcomes of all interventions should be evaluated and disseminated because even if imperfect programmes cannot be improved on, they provide valuable insights which can be used to inform the development of more effective programmes in the future. Not surprisingly, therefore, a number of recent reviews have strongly recommended that funding agencies should insist that future interventions include comprehensive and rigorous evaluation plans in order to determine why and how interventions, or components thereof, have succeeded or failed ${ }^{24,31}$. In order to achieve this, evaluation needs to be viewed as an integral component of an intervention from the outset, remain ongoing for the life of the project and ideally extend beyond closure to establish the generalisability, sustainability and cost-effectiveness of the intervention.

Most interventions have, to date, focussed more on assessing quantitative endpoints and have been much less concerned with assessing the progress of programme implementation (process evaluation). Regrettably, since the latter tends to employ a wide range of qualitative or 'soft' methods (interviews, diaries and observations), it tends to be dismissed as unrepresentative, and moreover, researchers and health professionals may resist critical scrutiny of their skills and procedures. However, process evaluation is crucial to provide an informed understanding of the factors responsible for success or failure of population obesity prevention programmes. In particular, process evaluation can, and should, be used to assess stakeholder perceptions and reactions to an intervention. Hitherto, the latter have seldom been involved in programme development and evaluation ${ }^{31}$, even though it seems intuitively logical that their input is vital in order to ensure that programmes are addressing their needs and concerns.

In relation to evaluating the endpoints of an intervention, traditionally impact evaluation of the immediate outcomes has been the most frequently employed as it can be built into the programme at the end stage and it is the easiest to do. In contrast, outcome evaluation of the longer term sustainability effects is much more complex, costly and is rarely undertaken. The distinction between impact and outcome evaluation is critically important because many childhood obesity prevention initiatives are designed to deliver 'low-dose' changes in dietary and physical activity behaviours, such that the impact on body size and composition and an overall improvement in obesity levels are unlikely to be immediately apparent or measurable within the life of a project, particularly if the project is of short duration.

The difficulty of evaluating obesity prevention initiatives should not be underestimated. Population health promotion programmes are complex and multifaceted and as a result, will require multiple approaches in order to evaluate effectiveness and efficiency. For example, school-based interventions typically comprise several intervention components, some of which target the individual, for example, through education and some of which target the environment through changing school food provision/choices. While a number of such studies have demonstrated positive outcomes, it is impossible to distinguish whether the individual or environmental components are operating independently or synergistically to effect behaviour change. More research is clearly needed to develop strategies which would permit the evaluation of the behaviour size effect associated with the separate and combined components of the intervention.

Ultimately, it is the evidence from outcome evaluation, particularly regarding sustainability and population impact, which health policy makers and public health 
strategists really need to know. Specifically, they are increasingly concerned to have answers to two key questions, 'Does the programme work?' and 'At what cost?' To date, the extent to which the outcomes of obesity prevention programmes have been achieved economically or in a manner which represents value for money has very rarely been reported. Applying standard costeffectiveness analysis to the Planet Health intervention, Wang et al. ${ }^{69}$ were able to demonstrate both the costeffective use and cost-saving of public funds. While this bodes well for school-based prevention programmes, it remains the only reported economic analysis of its kind in the literature and highlights the need to integrate behavioural and financial models in the evaluation of such programmes in the future. Putting a price on health outcomes or benefits will be a very difficult exercise for those who are unaccustomed to this facet of accountability, but given the increasingly limited resources for public health, researchers in the area will increasingly have to demonstrate hard results from their obesity prevention initiatives-good intentions will not be enough.

\section{Conclusion}

The prevention of childhood obesity has become a global priority but despite the extensive literature in the area, there are relatively few proven effective obesity prevention approaches for children at the present time. Thus, despite the large number of potentially useful interventions which have taken, or are currently taking place, it is still not possible to draw definitive conclusions and make specific recommendations about which components of these interventions have the potential to be rolled out on a larger scale, be sustainable in the medium to longer term and have a high likelihood of making a substantive impact on the prevalence of childhood obesity. Future efforts at obesity prevention need to learn from the failures and build on the successes of past interventions in order to develop the most effective evidence-based interventions for promoting and maintaining healthy weights in children. This review has identified some of the key methodological issues and gaps to moving this research base forward.

\section{References}

1 Lobstein T, Frelut ML. Prevalence of overweight among children in Europe. Obesity Reviews 2003; 4: 195-200.

2 Lobstein T, Baur L, Uauy R. Obesity in children and young people: a crisis in public health. Obesity Reviews 2004; 5(Suppl. 1): 4S-85S.

3 Whitaker RC, Wright JA, Pepe MS, Seidel KD, Dietz WH. Predicting obesity in young adulthood from childhood and parental obesity. New England Journal of Medicine 1997; 337: 869-73.

4 Parsons TJ, Power C, Logan S, Summerbell CD. Childhood predictors of adult obesity: a systematic review. International
Journal of Obesity and Related Metabolic Disorders 1999; 23(Suppl. 8): 1S-107S.

5 Freedman DS, Khan LK, Serdula MK, Dietz WH, Srinivasan SR, Berenson GS. Inter-relationships among childhood BMI, childhood height, and adult obesity: the Bogalusa Heart Study. International Journal of Obesity and Related Metabolic Disorders 2004; 28: 10-16.

6 Must A, Strauss RS. Risks and consequences of childhood and adolescent obesity. International Journal of Obesity and Related Metabolic Disorders 1999; 23(Suppl. 2): 2S-11S.

7 Power C, Lake JK, Cole TJ. Measurement and long-term health risks of child and adolescent fatness. International Journal of Obesity and Related Metabolic Disorders 1997; 21: 507-26.

8 Dietz WH. Childhood weight affects adult morbidity and mortality. Journal of Nutrition 1998; 128(Suppl. 2): 411S-4S.

9 Csabi G, Torok K, Jeges S, Molnar D. Presence of metabolic cardiovascular syndrome in obese children. European Journal of Pediatrics 2000; 159: 91-4.

10 Young-Hyman D, Schlundt DG, Herman L, De Luca F, Counts D. Evaluation of the insulin resistance syndrome in 5- to 10-year-old overweight/obese African-American children. Diabetes Care 2001; 24: 1359-64.

11 Must A, Jacques PF, Dallal GE, Bajema CJ, Dietz WH. Longterm morbidity and mortality of overweight adolescents. A follow-up of the Harvard Growth Study of 1922 to 1935. New England Journal of Medicine 1992; 327: 1350-5.

12 Hill AJ, Silver EK. Fat, friendless and unhealthy: 9-year old children's perception of body shape stereotypes. International Journal of Obesity and Related Metabolic Disorders 1995; 19: 423-30.

13 Hill AJ, Draper E, Stack J. A weight on children's minds: body shape dissatisfactions at 9-years old. International Journal of Obesity and Related Metabolic Disorders 1994; 18: 383-9.

14 Strauss RS. Childhood obesity and self-esteem. Pediatrics 2000; 105: e15.

15 Davison KK, Birch LL. Weight status, parent reaction, and self-concept in five-year-old girls. Pediatrics 2001; 107: $46-53$.

16 Kelder SH, Perry CL, Klepp KI, Lytle LL. Longitudinal tracking of adolescent smoking, physical activity, and food choice behaviors. American Journal of Public Health 1994; 84: $1121-6$.

17 Janz KF, Dawson JD, Mahoney LT. Tracking physical fitness and physical activity from childhood to adolescence: the muscatine study. Medicine and Science in Sports and Exercise 2000; 32: 1250-7.

18 Burke V, Beilin LJ, Dunbar D. Family lifestyle and parental body mass index as predictors of body mass index in Australian children: a longitudinal study. International Journal of Obesity and Related Metabolic Disorders 2001; 25: $147-57$.

19 Epstein LH, Myers MD, Raynor HA, Saelens BE. Treatment of pediatric obesity. Pediatrics 1998; 101: 554-70.

20 Muller MJ, Mast M, Asbeck I, Langnase K, Grund A. Prevention of obesity-is it possible? Obesity Reviews 2001; 2: $15-28$.

21 Summerbell CD, Ashton V, Campbell KJ, Edmunds L, Kelly S, Waters $\mathrm{E}$. Interventions for treating obesity in children. The Cochrane Database of Systematic Reviews 2003(3): CD001872.

22 Glenny AM, O'Meara S, Melville A, Sheldon TA, Wilson C. The treatment and prevention of obesity: a systematic review of the literature. International Journal of Obesity and Related Metabolic Disorders 1997; 21: 715-37.

23 Reilly JJ, Wilson ML, Summerbell CD, Wilson DC. Obesity: diagnosis, prevention, and treatment; evidence based answers to common questions. Archives of Disease in Childhood 2002; 86: 392-4. 
24 Summerbell CD, Waters E, Edmunds LD, Kelly S, Brown T, Campbell KJ. Interventions for preventing obesity in children. The Cochrane Database of Systematic Reviews 2005(3): CD001871.

25 Hardeman W, Griffin S, Johnston M, Kinmonth AL, Wareham $\mathrm{NJ}$. Interventions to prevent weight gain: a systematic review of psychological models and behaviour change methods. International Journal of Obesity and Related Metabolic Disorders 2000; 24: 131-43.

26 Epstein LH, Goldfield GS. Physical activity in the treatment of childhood overweight and obesity: current evidence and research issues. Medicine and Science in Sports and Exercise 1999; 31(Suppl. 11): 553S-9S.

27 Reilly JJ, McDowell ZC. Physical activity interventions in the prevention and treatment of paediatric obesity: systematic review and critical appraisal. Proceedings of the Nutrition Society 2003; 62: 611-9.

28 Story M. School-based approaches for preventing and treating obesity. International Journal of Obesity and Related Metabolic Disorders 1999; 23(Suppl. 2): 43S-51S.

29 Resnicow K. School-based obesity prevention. Population versus high-risk interventions. Annals of the New York Academy of Sciences 1993; 699: 154-66.

30 Doak CM, Visscher TL, Renders CM, Seidell JC. The prevention of overweight and obesity in children and adolescents: a review of interventions and programmes. Obesity Reviews 2006; 7: 111-36.

31 Flynn MA, McNeil DA, Maloff B, Mutasingwa D, Wu M, Ford $\mathrm{C}$, et al. Reducing obesity and related chronic disease risk in children and youth: a synthesis of evidence with 'best practice' recommendations. Obesity Reviews 2006; 7 (Suppl. 1): 7S-66S.

32 Green J, Tones K. Towards a secure evidence base for health promotion. Journal of Public Health Medicine 1999; 21: 133-9.

33 Stokols D. Establishing and maintaining healthy environments. Toward a social ecology of health promotion. The American Psychologist 1992; 47: 6-22.

34 Cohen DA, Scribner RA, Farley TA. A structural model of health behavior: a pragmatic approach to explain and influence health behaviors at the population level. Preventive Medicine 2000; 30: 146-54.

35 Sallis JF, Owen N. Ecological models of heath behaviour, 3rd ed. San Francisco: Jossey Bass, 2002.

36 Davison KK, Birch LL. Childhood overweight: a contextual model and recommendations for future research. Obesity Reviews 2001; 2: 159-71.

37 Luepker RV, Perry CL, McKinlay SM, Nader PR, Parcel GS, Stone EJ, et al. Outcomes of a field trial to improve children's dietary patterns and physical activity. The Child and Adolescent Trial for Cardiovascular Health. CATCH Collaborative Group. Journal of the American Medical Association 1996; 275: 768-76.

38 Caballero B, Clay T, Davis SM, Ethelbah B, Rock BH, Lohman $\mathrm{T}$, et al. Pathways: a school-based, randomized controlled trial for the prevention of obesity in American Indian schoolchildren. American Journal of Clinical Nutrition 2003; 78: 1030-8.

39 French SA, Stables G. Environmental interventions to promote vegetable and fruit consumption among youth in school settings. Preventive Medicine 2003; 37: 593-610.

40 Byers T. On the hazards of seeing the world through intervention-colored glasses. American Journal of Clinical Nutrition 2003; 78: 904-5.

41 Livingstone MB, Black AE. Markers of the validity of reported energy intake. Journal of Nutrition 2003; 133(Suppl. 3): 895S-920S.

42 Killen JD, Telch MJ, Robinson TN, Maccoby N, Taylor CB, Farquhar JW. Cardiovascular disease risk reduction for tenth graders. A multiple-factor school-based approach. Journal of the American Medical Association 1988; 260: 1728-33.

43 Whitaker RC. Obesity prevention in pediatric primary care: four behaviors to target. Archives of Pediatrics and Adolescent Medicine 2003; 157: 725-7.

44 Saarilehto S, Lapinleimu H, Keskinen S, Helenius H, Simell O. Body satisfaction in 8-year-old children after long-term dietary counseling in a prospective randomized atherosclerosis prevention trial. Archives of Pediatrics and Adolescent Medicine 2003; 157: 753-8.

45 Austin SB, Field AE, Wiecha J, Peterson KE, Gortmaker SL. The impact of a school-based obesity prevention trial on disordered weight-control behaviors in early adolescent girls. Archives of Pediatrics and Adolescent Medicine 2005; 159: $225-30$.

46 Monteiro PO, Victora CG. Rapid growth in infancy and childhood and obesity in later life-a systematic review. Obesity Reviews 2005; 6: 143-54.

47 Ekelund U, Ong K, Linne Y, Neovius M, Brage S, Dunger DB, et al. Upward weight percentile crossing in infancy and early childhood independently predicts fat mass in young adults: the Stockholm Weight Development Study (SWEDES). The American Journal of Clinical Nutrition 2006; 83: 324-30.

48 Ong KK, Emmett PM, Noble S, Ness A, Dunger DB. Dietary energy intake at the age of 4 months predicts postnatal weight gain and childhood body mass index. Pediatrics 2006; 117: e503-8.

49 Hediger ML, Overpeck MD, Maurer KR, Kuczmarski RJ, McGlynn A, Davis WW. Growth of infants and young children born small or large for gestational age: findings from the Third National Health and Nutrition Examination Survey. Archives of Pediatrics and Adolescent Medicine 1998; 152: 1225-31.

50 Garnett SP, Cowell CT, Baur LA, Fay RA, Lee J, Coakley J, et al. Abdominal fat and birth size in healthy prepubertal children. International Journal of Obesity and Related Metabolic Disorders 2001; 25: 1667-73.

51 Loos RJ, Beunen G, Fagard R, Derom C, Vlietinck R. Birth weight and body composition in young women: a prospective twin study. The American Journal of Clinical Nutrition 2002; 75: 676-82.

52 Arenz S, Ruckerl R, Koletzko B, von Kries R. Breast-feeding and childhood obesity-a systematic review. International Journal of Obesity and Related Metabolic Disorders 2004; 28 : $1247-56$

53 Butte NF. The role of breastfeeding in obesity. Pediatric Clinics of North America 2001; 48: 189-98.

54 Dewey KG. Is breastfeeding protective against child obesity? Journal of Human Lactation 2003; 19: 9-18.

55 Owen CG, Martin RM, Whincup PH, Smith GD, Cook DG. Effect of infant feeding on the risk of obesity across the life course: a quantitative review of published evidence. Pediatrics 2005; 115: 1367-77.

56 Tulldahl J, Pettersson K, Andersson SW, Hulthen L. Mode of infant feeding and achieved growth in adolescence: early feeding patterns in relation to growth and body composition in adolescence. Obesity Research 1999; 7: 431-7.

57 Butte NF, Wong WW, Hopkinson JM, Smith EO, Ellis KJ. Infant feeding mode affects early growth and body composition. Pediatrics 2000; 106: 1355-66.

58 Burdette HL, Whitaker RC, Hall WC, Daniels SR. Breastfeeding, introduction of complementary foods, and adiposity at $5 \mathrm{y}$ of age. American Journal of Clinical Nutrition 2006; 83: $550-8$.

59 Perry CL, Luepker RV, Murray DM, Hearn MD, Halper A, Dudovitz B, et al. Parent involvement with children's health promotion: a one-year follow-up of the Minnesota home team. Health Education Quarterly 1989; 16: 171-80.

60 Golan M, Weizman A, Apter A, Fainaru M. Parents as the exclusive agents of change in the treatment of childhood 
obesity. The American Journal of Clinical Nutrition 1998; 67: $1130-5$.

61 Golan M, Crow S. Targeting parents exclusively in the treatment of childhood obesity: long-term results. Obesity Reviews 2004; 12: 357-61.

62 Sallis JF, McKenzie TL, Conway TL, Elder JP, Prochaska JJ, Brown $\mathrm{M}$, et al. Environmental interventions for eating and physical activity: a randomized controlled trial in middle schools. The American Journal of Preventive Medicine 2003; 24: 209-17.

63 Kain J, Uauy R, Albala C, Vio F, Cerda R, Leyton B. Schoolbased obesity prevention in Chilean primary school children: methodology and evaluation of a controlled study. International Journal of Obesity and Related Metabolic Disorders 2004; 28: 483-93.

64 Gortmaker SL, Peterson K, Wiecha J, Sobol AM, Dixit S, Fox MK, et al. Reducing obesity via a school-based interdisciplinary intervention among youth: Planet Health. Archives of Pediatrics and Adolescent Medicine 1999; 153: 409-18.

65 Gortmaker SL, Cheung LW, Peterson KE, Chomitz G, Cradle $\mathrm{JH}$, Dart $\mathrm{H}$, et al. Impact of a school-based interdisciplinary intervention on diet and physical activity among urban primary school children: eat well and keep moving. Archives of Pediatrics and Adolescent Medicine 1999; 153: 975-83.

66 Killen JD, Robinson TN, Telch MJ, Saylor KE, Maron DJ, Rich $\mathrm{T}$, et al. The Stanford Adolescent Heart Health Program. Health Education Quarterly 1989; 16: 263-83.

67 Flores R. Dance for health: improving fitness in African American and Hispanic adolescents. Public Health Reports 1995; 110: 189-93.

68 Kumanyika SK. The minority factor in the obesity epidemic. Ethnicity and Disease 2002; 12: 316-9.

69 Wang LY, Yang Q, Lowry R, Wechsler H. Economic analysis of a school-based obesity prevention program. Obesity Research 2003; 11: 1313-24 